INTERNATIONAL DESIGN CONFERENCE - DESIGN 2018

https://doi.org/10.21278/idc.2018.0213

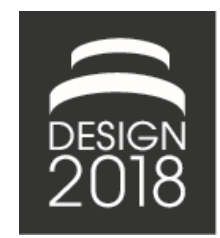

\title{
DERIVING A USE PHASE DATA STRATEGY FOR CONNECTED PRODUCTS: A PROCESS MODEL
}

\author{
J. Wilberg, L. Fahrmeier, C. Hollauer and M. Omer
}

\begin{abstract}
Data from connected products provides additional value because it enables companies to better understand their customers and their products' usage. However, companies struggle to identify use cases and derive a clear use phase data strategy. Existing process models for data analytics projects focus mainly on technical aspects and do not address strategy development. Thus, this paper presents a six step process model that assists companies in developing a use phase data strategy that turns data into value. An initial evaluation shows that the process model addresses important industry needs.
\end{abstract}

Keywords: big data analysis, internet of things (IoT), design methods

\section{Introduction}

Advances in information technology are a main driver for digitalisation and allow for the design of connected products and services (Porter and Heppelmann, 2014). Connectivity, as well as an increasing number of sensors, microprocessors and connectivity devices, creates an increasing amount of data that was not accessible to companies before. The data "generated during the use phase by the product itself (e.g. by sensors or microprocessors) and related product services (e.g. maintenance, repair, customer service, or mobile applications)" is called use phase data (Wilberg et al., 2017b).

Use phase data can be very valuable for both internal (e.g., product development or service department) and external stakeholders (e.g., customers). Connected products and services establish a connection between the manufacture and user that lasts until the end of the product's life (Porter and Heppelmann, 2015). Such data contains valuable insights about the behaviour of the customer and how the product and service are used (Wilberg et al., 2017b). Focusing on the customer allow for the development of market-tailored, and therefore competitive, products (Zhang and Fang, 2015). Use phase data is also essential to gain a better understanding of customer needs and provides a benefit to the company, especially if the insights are used for product development. Over-engineering is going to be a topic of the past, as well as functional over- or under-fulfilment (Porter and Heppelmann, 2014; Zhang and Fang, 2015). Aside from the improvement of the product itself, use phase data also helps companies to cut costs (Davenport, 2014), design new business models (Benta et al., 2017) and make data based decisions instead of ones made by intuition (McAfee and Brynjolfsson, 2012).

The challenge for engineering companies that are often less data oriented, is to select and process the relevant use phase data in order to create value for the different stakeholders (Lavalle et al., 2011; Wirth and Wirth, 2017). Companies would like to benefit from the aforementioned use cases, but struggle to identify novel and relevant use cases that build upon the availability of use phase data (Lavalle et al., 2011; Wirth and Wirth, 2017). They have a problem with adopting a data perspective and identifying use cases (Pols et al., 2016). Moreover, the complexity of the data and long product development processes in engineering companies make it necessary to plan ahead and define the 
required data points during the design phase (Köhler and Meir-Huber, 2014; Wilberg et al., 2017b). Different publications highlight the importance of structured planning that allows companies to identify suitable use cases, evaluate them, and plan their implementation (Davenport, 2014; Wirth and Wirth, 2017; Wilberg et al., 2017b). Thus, a main obstacle often occurs before data analytics tools even come into use.

The development of a clear strategy is the most important step before starting to collect data and using data analytics algorithms (Barton and Court, 2012; Davenport, 2014). Working with use phase data requires a clear plan to ensure that stakeholders collaborate whilst deriving and implementing use cases. However, a review of existing process models for data analytics initiatives revealed that they focus mostly on the processing and analysis of data, but not on the development of a use phase data strategy (Wilberg et al., 2017b). Many tools and algorithms for data analytics already exist, (Fayyad et al., 1996; Katal et al., 2013), but there is little support for the planning phase at the beginning.

Therefore, the objective of this paper is to support mechanical engineering companies especially in developing a tailored and suitable use phase data strategy which enables them to benefit from offering connected products and services. From the authors' perspective, the development of a process model seems suitable because process models provide orientation and guidance concerning the required process steps (Lindemann, 2009). The goal is to provide a process model that utilises existing research work as well as the practitioner's perspective. Therefore, the authors used triangulation to link existing research results with insights gained through expert interviews and industry case studies. This research approach led to the development of a six step process model that guides companies through the required tasks in order to identify suitable use cases and to derive a use phase data strategy. The process model was already applied in an industrial case study after it was developed (Wilberg et al., 2018).

The remainder of the paper is structured as follows. Chapter 2 presents the research methodology and results of the literature review on process models for strategy development and data analytics initiatives. Then Chapter 3 summarizes the requirements and introduces the process model that has been derived in order to support companies in developing a use phase data strategy. Chapter 4 provides insights from an initial evaluation of the process model. The paper then concludes with a summary and an outlook.

\section{Research foundation}

\subsection{Developed research methodology}

The previous discussion revealed that the development of a use phase data strategy helps to set clear objectives to extract value from use phase data. The objective of this paper is to support companies, which are either experienced, aspirational or inexperienced in handling use phase data, in developing a use phase data strategy. Providing a process model seems suitable because it guides companies through the steps required for the development of a use phase data strategy. Mechanical engineering companies especially often have little experience in deriving a use phase data strategy and thus do not know the necessary process steps and tasks. Figure 1 shows the developed research methodology.

Overall, the objective was to derive the process model in a systematic way and to build upon available research work and findings stemming from research and industry. For the development of the process model, three sources were available and the goal was to merge (triangulate) insights from all sources. Firstly, various publications provide process models for strategy development and data analytics projects. Secondly, the authors previously conducted industry case studies and an interview study.

The literature review on data and connectivity was conducted first and provided an understanding of the problems and opportunities that engineering companies face when dealing with use phase data. The insights revealed that companies struggle to identify suitable use case (e.g., predictive maintenance or automatic billing) and would benefit from a more structured process. Therefore, the next step was to search for process models and analyse them because they provide a structure and supporting methods to deal with the challenges connected with use phase data (Colas et al., 2014). As the second source for the triangulation, audio files from 15 interviews with experts from engineering companies were analysed (Wilberg et al., 2017a). Thirdly, two different case studies were analysed that were previously conducted 
with companies and aimed at developing a tailored use phase data strategy for them. Afterwards, the insights gained were used to formulate requirements for the process model, derive a structure for the process model, and identify suitable methods.

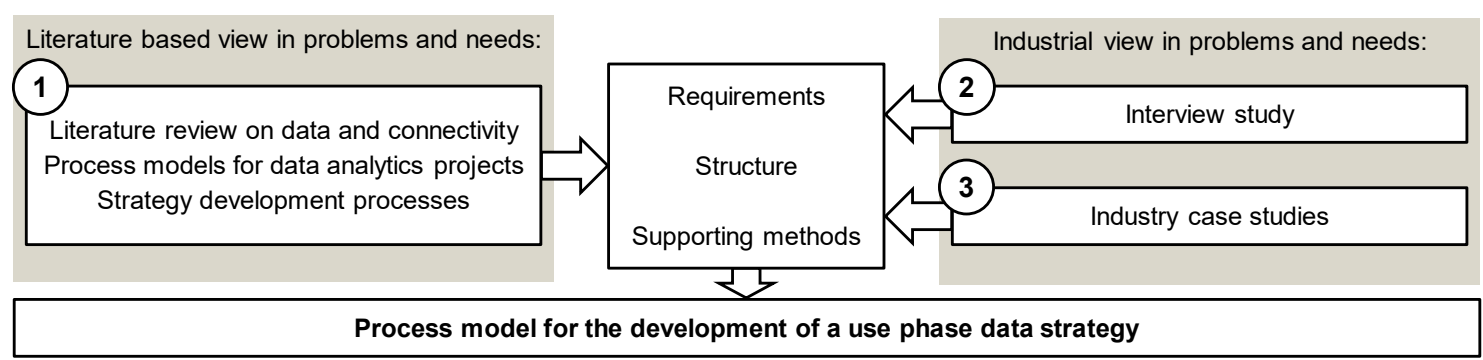

Figure 1. Research methodology for the deduction of a process model

\subsection{Literature review}

\subsubsection{The basics concerning use phase data}

Connected products often create a large amount of use phase data. Literature often refers to the term 'big data' when it comes to analysing and handling large datasets. Big data is characterized by up to five terms. The original $3 \mathrm{Vs}$ describing big data are volume, variety and velocity (Laney, 2001). Two more characteristics are veracity and value (Meier and Kaufmann, 2016). Use phase data is a subset of big data because it is limited to data generated during the use phase of a product.

The literature review concerning challenges and opportunities provided valuable insights. One of the major challenges is the lack of knowledge regarding what data is relevant for generating value (Brücher, 2013). Moreover, the problem of guaranteeing data security and privacy is not yet solved (van der Vegte, 2016). Also, a lack of support from the top management as well as failure to identify use cases cause issues for the companies (Pols et al., 2016). Furthermore, a study shows that nearly two-thirds of data analytics initiatives are not successful (Colas et al., 2014) and that only nineteen percent of companies use big data in their R\&D department (Bange et al., 2015). In general, mechanical engineering companies are less experienced in using big data compared to other industries like the financial sector, but they plan to strongly increase its application (Bange et al., 2015). Moreover, collecting and analysing data is not the core business of the engineering companies and they therefore struggle to integrate use phase data into their business (Davenport, 2014). Among other reasons, collecting data is more challenging in engineering because long development cycles require companies to formulate their data needs early on (Wilberg et al., 2017b). The aforementioned problems and the unsuccessful use of big data indicates the complexity of such projects and therefore the need for planning and adequate management. A strategy for use phase data enables companies to follow a clear line. The employees and departments involved are provided with a clear direction and objectives to pursue (Wilberg et al., 2017b). Overall, many publications confirmed the importance of a strategy to successfully turn data into value (Davenport, 2014; Kane et al., 2015; Gao et al., 2015; Wilberg et al., 2017b).

\subsubsection{Analysing process models for data analytics projects}

The next step was to evaluate existing process models for data analytics projects. The models were assessed using four criteria, which were derived from the findings in the previous section. The results of the analysis are summarised in Table 1. The goal was to check how much support is available to engineering companies when deriving a use phase data strategy. Due to the focus of this paper on engineering companies, one criterion was the consideration of the special challenges in this industry. Due to the confirmed importance of a strategy for the success of data initiatives, the support for strategy development is a second assessment criterion. Moreover, the identification of use cases is recognised as crucial, hence it is the third evaluation aspect (Wirth and Wirth, 2017; Wilberg et al., 2017b). 
Table 1. Results of an analysis of process models for data analytics projects

\begin{tabular}{|c|c|c|c|c|}
\hline References & $\begin{array}{l}\text { Step for strategy } \\
\text { development }\end{array}$ & $\begin{array}{l}\text { Generating and/or } \\
\text { identification of use } \\
\text { cases }\end{array}$ & $\begin{array}{l}\text { Supporting methods for } \\
\text { strategy development } \\
\text { or use cases }\end{array}$ & $\begin{array}{l}\text { Specification for } \\
\text { machine and plant } \\
\text { engineering industry }\end{array}$ \\
\hline Fayyad et al. (1996) & - & 0 & - & - \\
\hline Chapman et al. (2000) & 0 & - & - & - \\
\hline Lavalle et al. (2011) & 0 & 0 & - & - \\
\hline Almquist et al. (2015) & - & - & - & - \\
\hline Morabito (2015) & - & - & - & - \\
\hline Dutta and Bose (2015) & - & + & - & - \\
\hline EMC Corp. (2015) & 0 & 0 & - & - \\
\hline Gao et al. (2015) & & & - & - \\
\hline
\end{tabular}

To support the application of process models, it is helpful to provide supporting methods. An adequate method can facilitate the execution of a task and ensure systematic strategy development. Therefore, the existence of supporting methods for strategy development as well as for the identification of use cases was evaluated. A detailed analysis of the process models can be found in Wilberg et al. (2017b). The analysis covered both the descriptions of the process models and the individual steps.

It became clear that no process model considers the special needs of engineering companies. Furthermore, there was not enough support found for the identification of use cases. Only three out of fourteen even include a step similar to "generating and/or identification of use cases". Many models ("partially existing") only mention the importance of prioritisation. The methods for supporting the strategy development and for generating use cases are also insufficient. Moreover, a step relating to strategy development is missing in most of the models and only two models present a detailed step for the development. Some of the process models mention its importance but do not explain how to develop a strategy for data analytics projects (four models). Recalling the need for additional support during the planning and strategy development phase, existing process models do not address the need adequately.

\subsubsection{Analysing strategy development processes}

Due to the fact that a strategy is crucial to extract value from data, this paper further supports this task by providing a process model. In the context of this paper, a use phase data strategy "....defines which use cases a company plans to implement in order to create additional value for internal stakeholders (e.g., product development or service department) and/or external stakeholders (e.g. customers). The strategy also determines which data sources are used and what data quality requirements exist for the individual use cases. Furthermore, the data strategy includes a roadmap describing the timeline for the implementation of the different use cases and required tasks of the involved stakeholders. The strategy also describes the responsibilities of the stakeholders involved." (Wilberg et al., 2017b)

Strategy development is not a novel research field and therefore the goal was to use existing process models as a foundation to build upon. However, the combination of strategy development and use phase data is new. Nine process models were selected from literature. By comparing all of the process models using a systematic approach, eight basic steps were deduced. The approach that was used helped to make the superior order of required tasks visible. The extracted steps and the analysed process models are summarized in Table 2 . The order of the steps served as a basis for the developed process model. Furthermore, many process models also mentioned supporting methods for strategy development. 
Table 2. Results after analysing existing strategy development processes

\begin{tabular}{|c|c|c|c|c|c|c|c|c|c|}
\hline Task for strategy development & 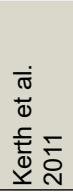 & 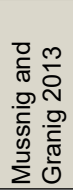 & 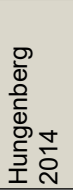 & $\begin{array}{l}\frac{1}{0} \\
\text { N } \\
0 \\
0 \\
\frac{0}{0} \\
\frac{1}{\omega}\end{array}$ & 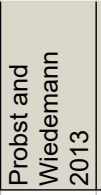 & 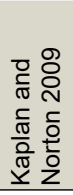 & 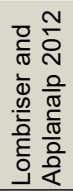 & 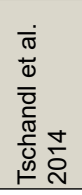 & 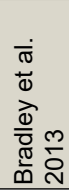 \\
\hline Analysis of the actual state & + & + & + & + & + & + & + & + & + \\
\hline Analysis of the target state & + & + & + & + & + & + & + & + & + \\
\hline $\begin{array}{l}\text { Deployment of alternatives to close the } \\
\text { gap between actual and target state }\end{array}$ & + & + & + & + & ○ & + & + & ○ & + \\
\hline Evaluation of the alternatives & + & + & + & + & ○ & + & + & - & + \\
\hline Deduction of strategic aims & + & + & + & + & + & + & ○ & - & - \\
\hline $\begin{array}{l}\text { Planning of initiatives for the } \\
\text { implementation strategy }\end{array}$ & + & + & + & + & + & + & + & + & + \\
\hline Scrutiny & + & + & - & + & - & + & + & + & + \\
\hline Learning & - & + & - & - & - & + & - & - & + \\
\hline \multicolumn{10}{|c|}{ ०: partially existing or existing in an undefined scope $\quad+$ : existing } \\
\hline
\end{tabular}

\subsubsection{Analysis of the interview study}

The next step was to focus on the needs within the industry. Therefore, the authors analysed a previously conducted interview study with 15 experts (Wilberg et al., 2017a). Due to the fact that the interviews focused on big data, not all results could be used for the development of a strategy for use phase data. One key result of the study was that a use phase data strategy is evaluated as important by the interviewees. Reasons are long product development processes, huge amounts of data, and the consideration of different objectives and use cases. The findings revealed diverse starting points for engineering companies because less than one third stated that they do not have a use phase data strategy. The same proportion stated that the development of one is planned, and $40 \%$ indicated that the company already has such a strategy. In contrast $20 \%$ of the experts stated that there is a need for support in identifying use cases. The results also show that strategy development is an iterative process, because companies want to implement use cases step-by-step and gain experience gradually.

\subsubsection{Analysis of two industry case studies}

Additionally, two different case studies were analysed. One was conducted in an industrial context together with an engineering firm and one in an academic context (Benta et al., 2017). The objective of the former was to identify and detail use cases that use data for production improvement within a 3Dprinting machine company. The latter dealt with customer-based services in an automotive context. Both case studies lasted for half a year. The first case study was especially helpful for the development of the process model because it revealed the tasks necessary to identify and evaluate use cases. The second one provided methods for the process model which are meant to support the single steps and tasks.

\subsection{Conclusion of the research foundation}

The findings of the triangulation reveal a mismatch between the problems and needs in comparison with the existing supporting models and processes. Companies that are not as data-literate struggle especially with developing a clear strategy. The discussion highlighted that a process model can guide companies through the development of a use phase data strategy. Until now, little research has been conducted on the development of a data strategy combining two fields. The process model should support the planning, the identification of use cases and the deduction of a roadmap especially. Insights from the analysis provide important input for formulating requirements for the process model in the next step. 


\section{The process model for the development of a use phase data strategy}

\subsection{Formulating the requirements}

The triangulation led to a list of requirements for a process model for the development of a use phase data strategy. The requirements are divided into formal ones and functional ones. The former include that a suitable process model has to be iterative (Wilberg et al., 2017b), incremental, logical regarding the order of the steps and adaptable. The latter means requirements which are related to single tasks and actions and therefore necessary sub-steps. The interviews and the literature review especially highlighted that the identification of use cases is challenging and needs be considered in a process model in a systematic way. Furthermore, it is necessary to document all the results and decisions made during the development process, which amongst other things is ensured by using supporting methods. The literature review also indicates that two main directions exist for deriving a use case. Firstly, the topdown (starting point: idea for a use case) and/or secondly, the bottom-up (starting point: available use phase data). Following a top-down approach means that a company defines use case first (e.g., predictive maintenance) and then designs the product in such a way that it generates the required data. Both approaches should be supported by the process model to respect the different starting points. Another requirement is that the process model is suitable for short and long projects. Moreover, it is important to support the identification of relevant stakeholders that can benefit from use phase data. This means it has to clarify who primarily benefits from the use phase data strategy. As mentioned in the introduction, the selection of the relevant data and its required quality is a challenging issue. Furthermore, the use phase data strategy needs to ensure that the available resources match the objectives of the project. To fulfil the requirements there has to be an interdisciplinary team, which ensures compliance. In general, industry-specific challenges like long product development processes shall be regarded.

\subsection{Introduction of the process model}

\subsubsection{Context of the process model and overview of the steps}

The insights derived from research and requirements formulated are used for the deduction of the process model. The steps and the order of the steps of the developed process model emerged from the strategy development processes and the process models for data analytics projects. The insights derived were used and transformed into the domain of use phase data. The model is divided into six steps, each with an explanation of the tasks, a suggestion of the supporting methods and a description of the intended results of the step. One step always covers two main tasks to which the title also refers. The visualisation of the process model with its six steps can be seen in Figure 2. It encourages users to jump between the steps and schedules a review at the end of the process. This review includes the evaluation of the objectives, thus seeing if they are still appropriate and have been accomplished during the strategy development. Furthermore, the selected use cases can be evaluated as well as the chosen the stakeholders that should benefit. Without a review there would be no lessons learned at the end.

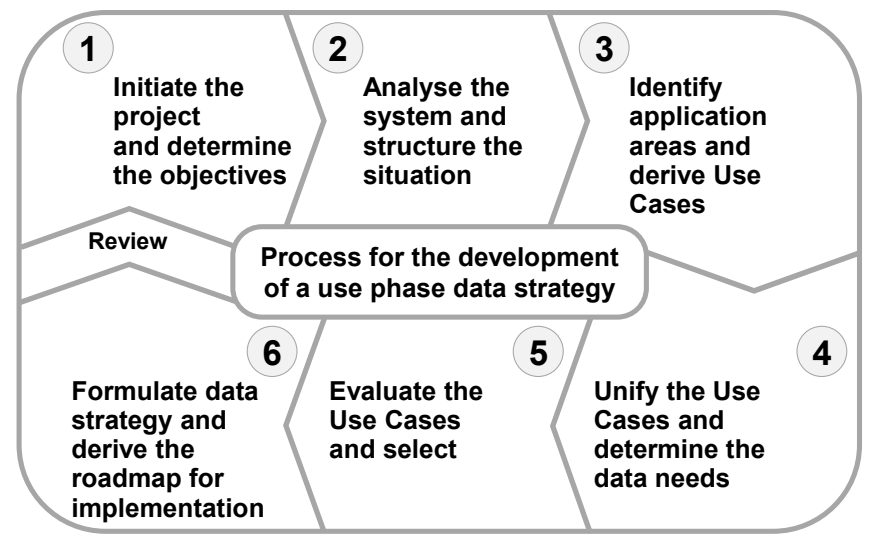

Figure 2. The six steps of the process model for the development of data strategy 
The process model is meant especially for engineering companies with or without data experience, in particular for the implementation of use phase data from products and services in the product development process. The aim is to generate value for internal and/or external stakeholders. Furthermore, the purpose of the process model is to support the development of a use phase data strategy and therefore focus on the planning of the implementation of use phase data. The challenges in Section 2.2. indicated that there is additional assistance needed for the planning phase because many existing research tools focus on data analytics. The process model therefore helps to identify use cases, because a lack of identification was revealed in the literature review. It is expected that the data's potential will be recognised and used with the support of the process model. Therefore, transparency regarding the relevant data has to be guaranteed. The output of the process model is a strategy, which defines relevant use phase data and its quality, the use cases for the use phase data and the value they bring. The strategy is afterwards used to further plan and prepare the implementation of the use cases.

\subsubsection{First step: Initiate the project and determine the objective}

Tasks: The first step of the process model starts with the initiation of a project. It is necessary for the management to declare a specific project for use phase data and therefore to signalise the importance of it (Dutta and Bose, 2015). The next step is to then compose a team which applies the process model and accompanies the strategy development. Use phase data also requires an interdisciplinary team to ensure widespread knowledge about technical topics, processes and operational performance. The development of a use phase data strategy necessitates bringing together domain specific (e.g., requirements engineering) and data analytics knowledge. Moreover, appointing a coach ensures focused discussions in order to achieve the objectives (VDI Gesellschaft 2011). The coach, or moderator, is responsible for adhering to the anticipated results of each step and for stopping the team from arguing over destructive topics and aspects on a too detailed and technical level. After the management has initiated the project it must also set the scope of the project and create an environment free from daily interruptions.

The second part is the formulation of the objectives, which is the first task for the team. Although the project objectives vary in different companies, the following aspects are recommended to be considered and to be defined. The team is responsible for determining a timeframe for the strategy development as well as a timeframe for the whole project itself, inclusive of implementation. Also, the members of the team must define the purpose of the strategy and the intended beneficiary. The latter means that a decision about the type of stakeholder has to be made. In addition, it is necessary to define the available resources, both in terms of money and personnel, to ensure that the capabilities of the company are not exceeded. This includes a cost limit for the project. Depending on the boundary conditions and the individual product portfolio of the company, an initial determination of the product group or class of interest has to be made. This depends especially on the size of the project and the resources.

Methods: For the second part, the determination of the objectives, the application of the SMARTmethod is recommended, which is an abbreviation for specific, measurable, accepted, realistic and time bound (Doran, 1981). The method helps the company to focus on the substantial objectives. Formulating a table of objectives is useful because it contains different aspects and the corresponding common objectives and therefore ensures not to miss a critical aspect (Müller-Stewens and Lechner, 2011).

Results: After the application of the tasks in step 1, a strategy development team exists, potentially with a coach. Further, a catalogue is set up containing objectives for the use of data strategy, the use cases and boundary conditions for the project.

\subsubsection{Second step: Analyse the system and structure the situation}

Tasks: After the initiation of the project and the definition of the objectives the second step can be performed. It starts with the analysis of the system, which means that on the one hand the environment of the company is analysed and on the other hand the company itself. It is not advisable to start developing the strategy the current situation is not clear (Schwaninger, 1987). Therefore, the analysis of the environment begins with the examination of influencing factors, which every company is confronted with (Norton and Kaplan, 2009; Johnson et al., 2011). This means, that general trends, technical progress, legislation etc. are regarded. Afterwards, an analysis of the market and customers follows to understand the usage of the product and service, which determines use cases later on (Hungenberg, 
2014). As part of the environmental analysis, the performance of direct and indirect competitors is analysed in order to identify competitive threats or opportunities. Of special interest is the analysis of existing use phase data strategies and use cases of competitors. The analysis of the company starts with the inspection of the product portfolio and the processes and includes the incorporation of the product lifecycle, the development process and, the stakeholders and the related goals. In addition, transparency concerning available use phase data, IT systems, and analytics tools is crucial. This is accompanied by the assessment of the own digital maturity level (Lavalle et al., 2011). Only if the status is clear the need for improvement can be formulated. The last point is the assessment of the current business model, the corporate strategy and if existing, the use phase data strategy. The reason for this reflection is that the team must be aware of the as-is situation to derive needs for a use phase data strategy.

The situational analysis provides comprehensive information. Therefore, it is crucial to structure the results and thus to merge the environment and company analysis (Lombriser and Abplanalp, 2012). At this point the already existing use phase data from products and services must be visible, because it later enables the identification of missing data for specific use cases (Wirth and Wirth, 2017). Using the gathered information, step 2 concludes with the review and detailing of the objectives defined during the first step to reinsure that the project can be brought off with the resources.

Methods: For the analysis of the environment the PESTEL-analysis, a market and customer analysis and the model of Porter about the five forces (Porter, 2008) are recommended to apply. Besides, maturity level models and stakeholder analyses support the company analysis. For structuring the situation some guiding questions, like "What is offered by our competitors?", the SWOT-analysis and a data map will be of great help (Benta et al., 2017).

Results: The findings of step 2 enable to obtain an overview concerning chances and risks for the development of a use phase data strategy. Information about products and services, data structure and existing use phase data in the company is provided and company's digital maturity level is assessed. Depending on the insights gained during this step, the objectives of step 1 are adjusted.

\subsubsection{Third step: Identify application areas and derive use cases}

Tasks: The third step firstly requires an ideation phase to identify application areas (e.g., R\&D or sales) which address the needs of internal and external stakeholders. The team uses its creativity and expert knowledge to brainstorm ideas for using the data from its products and services (Wirth and Wirth, 2017). At the beginning, technical feasibility and resource limitation should not be considered (Wirth and Wirth, 2017). Aside from creativity, it is also possible to research potential application areas within and outside the business for further ideas. In this step, companies need to decide whether to follow a topdown (define use cases as a starting point) and/or bottom-up (set available use phase data as a starting point) approach. From a data analytics perspective, two paths are possible: an explorative approach or a hypothesis test. The former means that data is processed to find patterns, the latter to confirm or reject a hypothesis. Additionally, the needs and interests of stakeholders must be identified for each idea.

Subsequently, the strategy development team must derive the final use cases from the previous ideas and application areas. This includes formulating the desired use cases, naming them and defining the expected additional value or benefit for the respective internal or external stakeholders. Afterwards, the use cases have to be examined for conformity with the objectives of the linked stakeholders. If the use case does not fit their needs and interests, its value is questionable. All suitable use cases are then documented in a structured way, for instance, by defining uniform templates or one pagers.

Methods: To identify application areas, creativity methods and workshops help to identify areas that could benefit from use phase data. A use case catalogue could support the ideation by providing external best practices. Furthermore, a stakeholder analysis is recommended as well as using a data map. Analysing the link between the stakeholders and the product's lifecycle further helps to identify new ideas that address special needs on a lifecycle basis. The data map created during step 2 visualises the available data and may help to identify some deficiencies or some opportunities to create synergies between different departments. It also supports the ideation in a visual way. For the second task, a use case template helps to document use cases in a structured way and thus to provide a clear overview.

Results: If step 3 is finished, an overview of possible application areas for the implementation of use phase data exists. Moreover, a collection of possible use cases in a uniform format is provided. 


\subsubsection{Fourth step: Unify the use cases and determine the need for data}

Tasks: After developing use cases, this collection will likely be too large for further processing. This is the reason why the first task is to unify the use cases and to filter them (e.g., defining exclusion criteria). Afterwards, the task is to identify connections between the remaining use cases in terms of engaged stakeholders and required data points. This helps not only to identify links among the use cases but also between use phase data and use cases. Subsequently, the team aggregates and clusters the use cases, which helps to form packages that are implemented later on in one release. The use case groups that emerge are compared to the objectives to ensure their suitability. To prepare the use cases for the final selection in step 5, the assessment criteria are defined. Then the use cases are prioritised and suitable ones are selected for determining the data needs in the next task (Wirth and Wirth, 2017).

Then it is important to gather the required information and to detail the relevant use cases. Therefore, the groups of stakeholders are asked, for example in workshops or interviews, for their opinion about the data needed for each use case and the related requirements (e.g., data quality) (Wirth and Wirth, 2017). The insights about available use phase data (Step 2) allow for the identification of a data delta (difference between available data and needed data) for each use case. If the data input needed for a use case is known, the data analytics approach can be determined as well as the required IT infrastructure.

Methods: For the unification of the use cases some guiding questions help, e.g. whether one additional use case can be realised by adding one extra data point. To make a selection for the determination of the data needs, methods for voting and decision making act as a support. One helpful method, for instance, is the business model canvas (Osterwalder and Pigneur, 2013). Although the process model is for developing a strategy, the canvas is suitable here. Either a business model shall be developed after the strategy, or the model is able to structure all aspects concerning the use case. Using the data enhanced Canvas + D helps to bring in the data perspective (Benta et al., 2017). Like in the previous step, the use case template supports the structured, detailed documentation of the use case. In case service-based use cases are relevant, a service blueprint is suitable to uncover required processes during later operations.

Results: The outcome of this step is knowledge about the interdependencies of the use cases and a selection of use cases with a degree of detail for further comparison and evaluation. The step also provides the documentation of the selected use cases, which defines, for instance, the data requirements.

\subsubsection{Fifth step: Evaluate and select the use cases}

Tasks: Although the list is shortened in step 4, there will remain too many use cases for implementation. Thus, the first task in step 5 is the evaluation of the use cases on two levels. The first level evaluates the use cases with respect to the catalogue of objectives from step 1. Therefore, some issues help to structure the examination in regard of the topic's suitability, acceptance and feasibility (Sternad, 2015). The questions are in the same order; "Is it possible to fulfil the objectives with the use case(s)?", "How is the performance and value estimated?", "Is it possible to implement the use case with the capabilities of the company?". After the objectives have been reconsidered, the next task is the prototypical testing. Because it is not certain that the data and the associated data quality, which was identified in step 4 , is adequate to generate the desired insights, and therefore the expected value, a test is necessary (Wirth and Wirth, 2017). If the feasibility of extracting value from a small set of data is proven, the evaluation on the second level can be carried out. On this level, each use case itself is regarded with all the information collected so far. The evaluation criteria are the benefits of a use case, innovativeness, complexity (e.g., implementation or IT systems), estimated costs, and the time span for implementation. The evaluation is accompanied by the second action of step 5: the selection of one or more use cases depending on the resources and the effort required for the use cases. Firstly the criteria are compared, if applicable, with a holistic assessment scheme for all criteria (Norton and Kaplan, 2009). Secondly, one or more use cases are selected for implementation based on the assessment.

Methods: The catalogue of objectives that was derived earlier helps to evaluate the remaining use cases. To align the internal and external perspective, the SWOT-analysis from step 2 makes the strengths and weaknesses visible. These evaluation results allow for an assessment of the feasibility of the use cases and provide the additional information needed to complete the use case template. To evaluate the financial feasibility, budgeting is crucial. Further, the service blueprint may give some indication of the complexity of a data-driven service. For the final selection, assessment schemes provide support. 
Results: In sum, this step provides an extensive evaluation of the use cases based on different criteria. This step leads to one or more use cases that provide insights with a high level of detail.

\subsubsection{Sixth step: Formulate the data strategy and derive the roadmap for implementation}

Tasks: Once a final selection of use cases exists, the formulation of the strategy follows. The strategy should be written down to document the objectives, the expected competitive advantage of the use cases and the scope, i.e. the market and/or customer segment the use case shall serve (Norton and Kaplan, 2009). Formulating a strategy alone is not enough for a successful implementation and thus a consistent visualisation of the use phase data strategy is the first step to preparing its implementation. The strategy can be visualised using a strategy map, which divides the use cases into the four perspectives of the balanced scorecard. Based on the number of use cases, multiple scorecards can exist.

To prepare the implementation of the use phase data strategy, a roadmap helps to determine its timeframe and related responsibilities. Likewise, the assignment of departments and use cases takes place. With the aid of the balanced scorecard, success factors for the use case are already formulated and can be incorporated into the roadmap. Due to the fact that technical products have long development cycles, companies need to determine the need for additional devices or technologies which generate, collect and process use phase data. A synchronization with the product roadmap is thus advised. Hence, the implementation may not only require an adaption of products and services, but also IT infrastructure, processes, data analytics tools, organizational structures or professional skills.

Methods: As mentioned above, the strategy map and the balanced scorecard aim to formulate the strategy (Norton and Kaplan, 2009). Also the Canvas +D from step 4 supports the strategy development by structuring important aspects, especially if a business model is to be developed.

Results: Ultimately, the strategy document ensures transparency, a clear direction, and helps to draw a roadmap. The roadmap gives a visual overview of the timeframe, the respective responsibilities and success factors and the activities necessary for the implementation of the use phase data strategy.

\section{Initial evaluation and reflection}

The objective was to develop a process model that provides theoretical and practical value. Thus, a four hours long workshop with six experts from industry was conducted. The first part included a discussion concerning the importance of a use phase data strategy. The experts confirmed the importance of a clear strategy. In addition, they agreed that a process model helps companies to develop a strategy in a structured way. At the end, the manual for the process model was handed to the experts which included a questionnaire with three parts. Four of the participants returned this. The first part asked to evaluate the present situation of the company. Second, the process model was evaluated as a whole. Third, the six steps were evaluated individually concerning three criteria: "the objective of the step is sensible", "the tasks are clearly understandable" and "the result is sensible".

The majority (3 out of 4) stated that their company is experienced with data. Only one assessed the situation as aspirational. The next question asked for the status of the use phase data strategy. Three experts said that they are developing one right now and mentioned that the development is planned. Afterwards, the experts evaluated whether all of the important steps are included in the process model. Three marked "somewhat agree" and one "somewhat disagree". The order of the steps was also evaluated as logical (two experts voted "agree", one "somewhat agree" and one "rather not agree"). The two experts with less positive feedback stated that they would prefer a more agile approach. The application of the process model differs widely when using it as a basis for discussion compared to using it as a top-down strategy development (regardless of use cases). The evaluation of the six steps was quite consistent. The experts assessed nearly all of the three criteria mentioned above at least as "somewhat agree". This leads to the conclusion that the process model and every step with its tasks, expected results and suggested supporting methods are accepted and considered useful.

Overall, the process model for the development of a use phase data strategy meets the requirements. The developed model consists of six steps each with single tasks, which makes it incremental and adaptable. It is not necessary to perform every step due to different starting points. The process model provides a framework and different paths exist within. Furthermore, the suggested methods are a proposal. Companies can adapt them if they are more familiar with other ones. 


\section{Summary and outlook}

Modern products are often connected and produce use phase data which is constantly transmitted to the manufacturer. Use phase data contains valuable insights about product usage and customer preferences, which enables, for instance, the reduction of over-engineering. These new opportunities come at a price, because data is not necessarily of value in itself. Companies face new challenges on a planning, organizational and technological level. The literature review showed that the development of a use phase data strategy helps companies to identify suitable use cases. Inexperienced companies in particular struggle to understand how use phase data can provide value for internal and external stakeholders. A structured process could thus help to navigate companies through the steps needed for developing a use phase data strategy. However, existing process models mainly focus on the analytics-related tasks. This paper addresses this need by providing a six step process model that supports companies in deriving and selecting suitable use cases that provide additional value. The developed process model describes on a detailed level the required task, supporting methods and results leading to a use phase data strategy and an initial roadmap. The manual for the process model further improves its applicability. A workshop with participants from engineering companies revealed the importance of a use phase data strategy to provide a clear vison and direction for activities. An initial evaluation of the process model showed that experts from industry rate it as helpful and the order of the steps as logical. The description of each step also received positive feedback concerning its objective, intended result and comprehensibility.

The evaluation within a group of four is only preliminary and shows that the process model provides helpful support. However, an in-depth evaluation of the process model in an industrial context is needed and already in progress with three companies. The model itself will be evaluated as well as the application of the model. The objective is to understand the difficulties encountered when using the derived process model in an industrial application. Insights from an initial application of the process model at a mechanical engineering company are published in a separate paper (Wilberg et al., 2018).

\section{Acknowledgment}

We thank the German Research Foundation (Deutsche Forschungsgemeinschaft -DFG) for funding this project as part of the collaborative research center 'Sonderforschungsbereich 768 - Managing cycles in innovation processes - Integrated development of product-service systems based on technical products.

\section{References}

Bange, C., Grosser, T. and Janoschek, N. (2015), Big Data Use Cases 2015: Getting real on data monetization, Würzburg, BARC - Institut: Business Application Research Center.

Barton, D. and Court, D. (2012), "Making advanced analytics work for you", Harvard Business Review, Vol. 90 No. 10, pp. $78-83$.

Benta, C., Wilberg, J., Hollauer, C. and Omer, M. (2017), "Process Model for Data-Driven Business Model Generation”, 21st International Conference on Engineering Design (ICED17), Vancouver, Canada, August 21-25, 2017.

Brücher, C. (2013), Rethink Big Data, 1st ed, mitp, Heidelberg.

Colas, M., Finck, I., Buvat, J., Nambiar, R. and Singh, R.R. (2014), Cracking the Data Conundrum: How Successful Companies Make Big Data Operational, Capgemini Consulting.

Davenport, T.D. (2014), Big Data@work: Dispelling the myths, uncovering the opportunities, Harvard Business Review Press, Boston, Massachusetts.

Doran, G.T. (1981), “There's a S.M.A.R.T. Way to Write Management's Goals and Objectives”, Management Review, Vol. 60 No. 11, pp. 35-36.

Dutta, D. and Bose, I. (2015), "Managing a Big Data project. The case of Ramco Cements Limited", International Journal of Production Economics, Vol. 165, pp. 293-306. https://doi.org/10.1016/j.ijpe.2014.12.032

Fayyad, U.M., Piatetsky-Shapiro, G. and Smyth, P. (1996), "From Data Mining to Knowledge Discovery in Databases", AAAC - American Association for Artificial Intelligence, Vol. 17 No. 3, pp. 37-54.

Gao, J., Koronios, A. and Selle, S. (2015), "Towards A Process View on Critical Success Factors in Big Data Analytics Projects", Twenty-first Americas Conference on Information Systems, Puerto Rico.

Hungenberg, H. (2014), Strategisches Management in Unternehmen: Ziele - Prozesse - Verfahren, 8th ed., Springer Gabler, Wiesbaden. https://doi.org/10.1007/978-3-658-06681-9

Johnson, G., Scholes, K. and Whittington, R. (2011), Strategisches Management: Eine Einführung ; Analyse, Entscheidung und Umsetzung, 9th updated ed., Pearson Studium, München. 
Kane, G.C., Palmer, D., Nguyen Phillips, A., Kiron, D. and Buckley, N. (2015), Strategy, Not Technology, Drives Digital Transformation, MIT Sloan Management Review and Deloitte University Press.

Katal, A., Wazid, M. and Goudar, R.H. (2013), "Big data. Issues, challenges, tools and Good practices", 2013 Sixth International Conference on Contemporary Computing (IC3), Noida, India, August 8-10, 2013, IEEE, pp. 404-409.

Köhler, M. and Meir-Huber, M. (2014), \#Big Data in \#Austria: Österreichische Potenziale und Best Practice für Big Data, Wien, BMVIT Bundesministerium für Verkehr, Innovation und Technologie.

Laney, D. (2001), 3D Data Management: Controlling Data Volume, Velocity, and Variety, Meta Group.

Lavalle, S., Hopkins, M.S., Lesser, E., Shockley, R. and Kruschwitz, N. (2011), "Big Data, Analytics and the Path from Insights to Value", MIT Sloan Management Review, Vol. 52 No. 2, pp. 20-31.

Lindemann, U. (2009), Methodische Entwicklung technischer Produkte: Methoden flexibel und situationsgerecht anwenden, VDI-Buch, 3rd corrected ed., Springer, Berlin. https://doi.org/10.1007/978-3-642-01423-9.

Lombriser, R. and Abplanalp, P.A. (2012), Strategisches Management: Visionen entwickeln, Erfolgspotenziale aufbauen, Strategien umsetzen, 5th ed., Versus, Zürich.

McAfee, A. and Brynjolfsson, E. (2012), "Big Data: The Management Revolution", Harvard Business Review, Vol. 90 No. 10, pp. 60-68.

Meier, A. and Kaufmann, M. (2016), SQL- \& NoSQL-Datenbanken, Springer, Berlin. https://doi.org/10.1007/9783-662-47664-2

Müller-Stewens, G. and Lechner, C. (2011), Strategisches Management: Wie strategische Initiativen zum Wandel führen, 4th ed., Schäffer-Poeschel, Stuttgart.

Norton, D.P. and Kaplan, R.S. (2009), Der effektive Strategieprozess: Erfolgreich mit dem 6-Phasen-System, Management 2009, 1. Aufl., Campus, Frankfurt am Main.

Osterwalder, A. and Pigneur, Y. (2013), Business model generation: A handbook for visionaries, game changers, and challengers, Wiley\&Sons, New York.

Pols, A., Heidkamp, P. and Erwin, T. (2016), Mit Daten Werte schaffen 2016: Pressekonferenz, Berlin, BITKOM Bundesverband Informationswirtschaft, Telekommunikation und neue Medien e.V.

Porter, M.E. (2008), "The five competitive forces that shape strategy", Harvard Business Review, Vol. 86 No. 1, pp. 57-71.

Porter, M.E. and Heppelmann, J.E. (2014), "How Smart Connected Products Are Transforming Competition", Harvard Business Review, Vol. 92 No. 11, pp. 64-88.

Porter, M.E. and Heppelmann, J.E. (2015), "How Smart Connected Products Are Transforming Companies", Harvard Business Review, Vol. 93 No. 10, pp. 53-71.

Schwaninger, M. (1987), “A practical approach to strategy development”, Long Range Planning, Vol. 20 No. 5 , pp. 74-85.

Sternad, D. (2015), Strategieentwicklung kompakt: Eine praxisorientierte Einführung, essentials, Springer Gabler, Wiesbaden. https://doi.org/10.1007/978-3-658-10367-5

van der Vegte, W.F. (2016), "Taking Advantage of Data Generated by Products. Trends, Opportunities and Challenges", Volume 1B: 36th Computers and Information in Engineering Conference, Charlotte, North Carolina, USA, August 21-24, 2016, ASME.

Wilberg, J., Kalla, T., Fetscher, M., Rimböck, F., Hollauer, C. and Omer, M. (2018), “Development of a Use Phase Data Strategy for Connected Products - A Case Study in Industry (accepted)", PICMET '18: Managing Technological Entrepreneurship: The Engine for Economic Growth, Honolulu, USA, August 19-23, 2018.

Wilberg, J., Schäfer, F., Kandlbinder, P., Hollauer, C., Omer, M. and Lindemann, U. (2017a), "Data Analytics in Product Development: Implications from Expert Interviews", 2017 IEEE International Conference on Industrial Engineering and Engineering Management (IEEM), Singapur, December 10-12, 2017.

Wilberg, J., Triep, I., Hollauer, C. and Omer, M. (2017b), "Big Data in production development: Need for a data strategy", PICMET '17: Technology Management for Interconnected World, Portland, USA.

Wirth, N. and Wirth, R. (2017), "How to meet the four key challenges to turn Big Data into smart data-driven solutions", Research World, Vol. 2017 No. 64, pp. 31-36. https://doi.org/10.1002/rwm3.20516

Zhang, J. and Fang, X. (2015), "On-site usage-data drives industrial robot design improvement", 2015 IEEE International Conference on Robotics and Biomimetics (ROBIO), Zhuhai, December 6-9, 2015, IEEE, pp. 704-709.

Julian Wilberg, Research Associate

Technical University of Munich, Product Development and Lightweight Design

Boltzmannstr. 15, 85748 Garching, Germany

Email: wilberg@pl.mw.tum.de 